\title{
Self-sealing capacity of argillite samples
}

\author{
Alice Di Donna ${ }^{1, *}$, Pascal Charrier ${ }^{1}$, Simon Salager ${ }^{1}$, Pierre Bésuelle $^{1}$ \\ ${ }^{1}$ Univ. Grenoble Alpes, CNRS, Grenoble INP, 3SR, 38000 Grenoble, France
}

\begin{abstract}
Many countries are currently facing the issue of finding a proper solution to store radioactive wastes coming from nuclear energy production plants. The possibility to store them in underground tunnels is largely considered and investigated. In France, Andra (Agence Nationale pour la gestion des Déchets Radioactifs) selected the Callovo-Oxfordian rock clay (COx) situated in the Meuse/Haute Marne site (France) between 400 and $600 \mathrm{~m}$ depth as possible host rock deposit. The excavation of the storage tunnels is expected to create a fractured zone around galleries. However, the factures will be then gradually re-saturated by the underground water coming from the surrounding rock mass and the fractures are expected to self-seal in contact with water, thanks to the swelling potential of COx. The capacity of self-sealing of COx, i.e. closing of fractures after water contact and possibly restoring of hydraulic permeability, is thus of primary interest for the safety of the storage system with respect to water, gas and solutes transport. In the work presented in this paper, the self-sealing behaviour of the COx argillite was investigated through x-ray tomography. The tested samples show significantly different responses depending on the zone where they have been collected on site. The results of mineralogical analyses (x-ray diffraction) are used to understand the observed phenomena.
\end{abstract}

\section{Introduction}

Many countries are currently facing the issue of finding a proper solution to store radioactive wastes coming from nuclear energy production plants. The possibility to store them in underground tunnels is largely considered and investigated. In France, Andra (Agence Nationale pour la gestion des Déchets Radioactifs) selected the CallovoOxfordian clay rock (COx) situated in the Meuse/Haute Marne site between 400 and $600 \mathrm{~m}$ depth as possible host rock deposit. This choice was driven, among other reasons, by the very low permeability and diffusion associated to high retention capacity for radionuclides of this material. However, it is known that the excavation of the underground tunnels for waste storage will induce a damaged zone in the host rock characterised by a network of fractures close to the gallery wall. The hydraulic conductivity of this zone with respect to water, gas and solutes transport would consequently increase. On the other hand, once the tunnels will be filled and closed, the fractures will be gradually re-saturated by the water coming from the host rock. In contact with water, the $\mathrm{COx}$ is expected to swell and therefore the fractures to self-seal, thanks to the presence of active clays in the clay matrix. It is clear that the self-sealing capacity of $\mathrm{COx}$ is of primary interest for the safety of the storage site. In this work, it was studied experimentally, through x-ray tomography and digital image correlations. Various zones of the rock mass, sizes of fractures and orientations of the bedding plane were investigated to study the variability of the response. In the following, the experimental techniques adopted are briefly described. Then selected results are presented and mineralogical analyses are used to interpret the observed phenomena.

\section{Experimental campaign}

\subsection{Tested material}

On Andra site, the storage tunnel is located at $490 \mathrm{~m}$ depth, in the so-called clay (Argillite) Unit (U.A.). Above this layer, from 450 to $470 \mathrm{~m}$ depth there is the so-called Transition Unit (U.T.), over which there is the SilicateCarbonate Unit (U.S.C.). The three units differ in terms of mineralogical composition, the U.A. being richer in clays, the U.S.C. being richer in carbonates and the U.T. being a transition between the two others (Conil et al., 2018). In this study, samples coming from the U.A. (cores EST53644 and EST58102) and the U.T. (cores EST57243 and EST57261) were tested. The in-situ depth and initial water content of the COx cores used are presented in Fig. 1 (triangles), together with data collected from other studies (dots) available in the literature on the same material. Combining these data with those presented by Conil et al. (2018), it appears that the in-situ water content of COx ranges between 2 and $9 \%$ and the void ratio between 0.15 to 0.25 and the material is considered saturated $\left(\mathrm{G}_{\mathrm{s}}=2.7\right)$.

The values measured in this study for the U.A. samples were in the rage between 6 and $8 \%$ (Fig. 1). The U.T. samples showed generally low initial water content (in the order of 1.5 to $2 \%$ ), which was associated to the very low void ratios, also measured in the laboratory through the Archimedes' technique. Even in this case, the

\footnotetext{
* Corresponding author: alice.didonna $@, 3$ sr-grenoble.fr
} 
degree of saturation was therefore computed to be close to the unit.

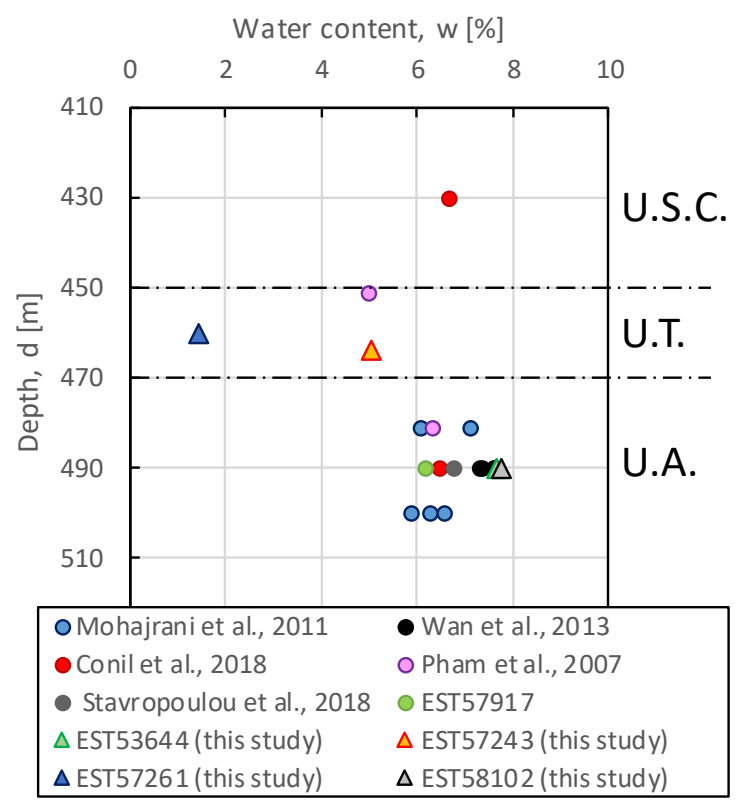

Fig. 1. In-situ position and water content of the tested samples.

\subsection{Samples preparation}

COx cylindrical samples $20 \mathrm{~mm}$ height and 8 to $9 \mathrm{~mm}$ in diameter were cut from the cores received from the site. Each sample was then cut in two semi-cylinders in order to create an artificial discontinuity (Fig. 2). Finally, each of them was glued on a semi-cylindrical shell. The two half-shells were glued together with a spacer controlling the size of the discontinuity. Varying discontinuity sizes ranging between 75 and $490 \mu \mathrm{m}$ were tested. The samples were cut with various orientations with respect to the insitu bedding plane and in situ principal stresses in order to investigate the effect of anisotropy on the material response (Fig. 3). Synthetic water prepared in the laboratory according to the real in-situ salinity was used. Other specimens equal to the tested ones were used to measure water content and suction at different stages during samples preparation. This was done to monitor the water loss during the preparation procedure and be aware of the hydraulic conditions during the experiments. Before testing, the samples were re-equilibrated in a chamber with controlled temperature of $30^{\circ} \mathrm{C}$ and relative humidity of $90 \%$ for 48 hours.

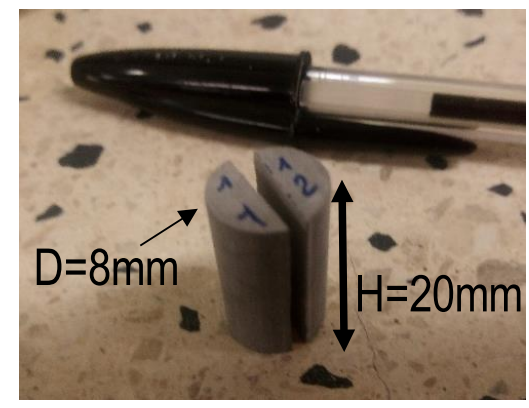

Fig. 2. Final size of the cylindrical samples with the artificial fracture.

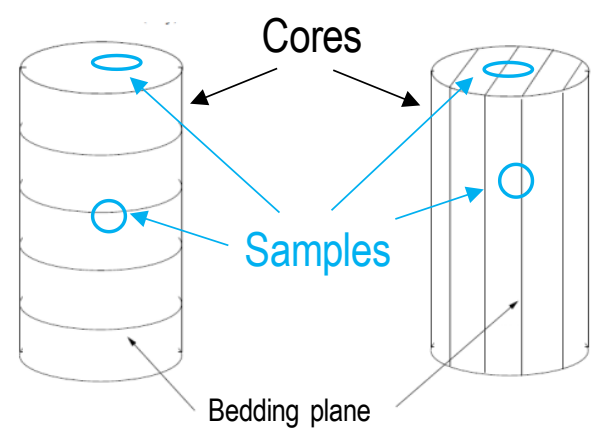

Fig. 3. Samples cutting from the COx cores with different orientations with respect to bedding plane.

\subsection{Testing program}

A summary of the performed experiments with the corresponding experimental conditions is provided in Table 1. Three testing phases were considered: the discontinuity was either saturated by water vapour $(\mathrm{V})$, or by liquid water (W) or dried by dry air circulation (D). With reference to Fig. 1, samples 3132, 4142, 8182 and 9192 were cut from core EST53644 (U.A. at around 490 m depth), samples AH1112 and AV1112 from core EST57243 (U.T. at around $463 \mathrm{~m}$ depth), samples BH4142 and BV3132 from core EST 57261 (U.T. at around $460 \mathrm{~m}$ depth) and samples V3132, V4142 and H2122 from core EST58102 (U.A. at around $490 \mathrm{~m}$ depth).

Table 1. Experimental program.

\begin{tabular}{|c|c|c|c|c|}
\hline Test & $\begin{array}{l}\text { Geologica } \\
1 \text { unit }\end{array}$ & $\begin{array}{l}\text { Bedding } \\
\text { plane }\end{array}$ & $\begin{array}{l}\text { Loading } \\
\text { path }\end{array}$ & $\begin{array}{c}\text { Fracture } \\
\text { size } \\
{[\mu \mathrm{m}]}\end{array}$ \\
\hline 3132 & U.A. & $\begin{array}{c}\text { Vertical } \\
(\text { fracture } \\
\left.\text { inclined } \approx 30^{\circ}\right)\end{array}$ & V-W-D & 75 \\
\hline 4142 & U.A. & $\begin{array}{c}\text { Vertical } \\
(\text { fracture } \\
\left.\text { inclined } \approx 30^{\circ}\right)\end{array}$ & V-W-D & 150 \\
\hline 8182 & U.A. & $\begin{array}{c}\text { Vertical } \\
(\text { fracture } \\
\left.\text { inclined } \approx 30^{\circ}\right)\end{array}$ & D-W & 300 \\
\hline 9192 & U.A. & $\begin{array}{c}\text { Vertical } \\
(\text { fracture } \\
\left.\text { inclined } \approx 30^{\circ}\right)\end{array}$ & D-W & 425 \\
\hline AH1112 & U.T. & Horizontal & V-W & 430 \\
\hline AV1112 & U.T. & $\begin{array}{l}\text { Vertical } \\
\text { (parallel } \\
\text { fracture) } \\
\end{array}$ & V-W & 240 \\
\hline BH4142 & U.T. & Horizontal & V-W-D & 490 \\
\hline BV3132 & U.T. & $\begin{array}{l}\text { Vertical } \\
\text { (parallel } \\
\text { fracture) } \\
\end{array}$ & V-W & 165 \\
\hline V3132 & U.A. & $\begin{array}{l}\text { Vertical } \\
\text { (parallel } \\
\text { fracture) }\end{array}$ & W & $\begin{array}{l}\text { Not } \\
\text { regular }\end{array}$ \\
\hline V4142 & U.A. & $\begin{array}{c}\text { Vertical } \\
\text { (perpendicular } \\
\text { fracture) }\end{array}$ & W-D & 75 \\
\hline H 2122 & U.A. & Horizontal & W & 300 \\
\hline
\end{tabular}


The opening and closure of the discontinuity during the different phases was followed by x-ray tomography, regularly scanning the samples. The scans frequency was higher during the saturation by water phases were the material was expected to react faster. The first 8 experiments in Table 1 were carried with the tomography utilities of the 3SR Laboratory in Grenoble. The last 3 tests were performed in beamline ID19 at the European Synchrotron Radiation Facility (E.S.R.F) in Grenoble. In the first case, the images resolution was ranging between 15 and $7 \mu \mathrm{m}$ while in the second case a resolution of 0.7 $\mu \mathrm{m}$ was reached.

\subsection{Experimental setup}

The experimental setup is illustrated in Fig. 4. A pump circulates the dry air, the water vapour or the liquid synthetic water contained in the reservoir to the sample discontinuity. A sensor is used to monitor the relative humidity and temperature in the reservoir. During the phases of saturation by water, the discontinuity was simply filled by water, avoiding circulation to reduce the risk of material erosion. This was done to isolate the selfsealing behaviour and be able to study it deeply.

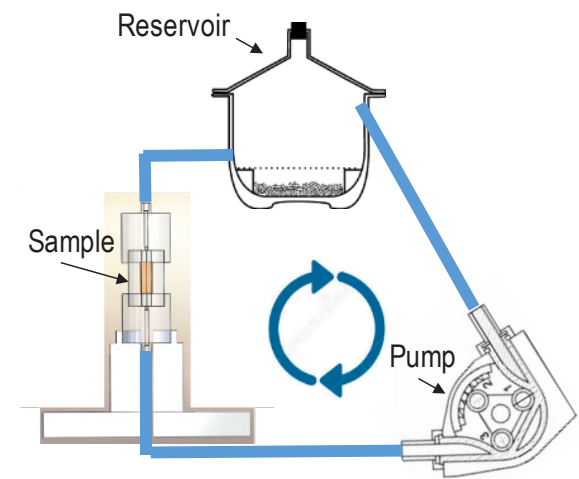

Fig. 4. Experimental device.

\section{Results}

Selected results of x-ray tomography are presented hereafter. The results of $\mathrm{x}$-ray diffraction analyses are discussed in the following as a means to justify the observed behaviour.

\subsection{X-ray tomography images}

Fig. 5 shows the central slice (in the middle of the sample) of test 4142 during different experimental phases, i.e. after 1 day of saturation by vapour and after 1 and 10 subsequent hours of saturation by water. Comparing with the reference scan obtained before the beginning of the experiment (which is not presented here), the saturation by vapour phase does not present significant evolutions. Conversely, the sample reacted very rapidly when it was put in contact with water: the clay matrix swelled, and the artificial crack started closing after less than 1 hour. After 10 hours the closing looked almost completed, at least at the scale and resolution of these images. This sample is considered representative of the U.A. as the other similar samples had similar response. At this scale, the effect of the bedding plane orientation seems limited. Smaller fractures reached closure more rapidly, while the largest ones show a peeling effect on the discontinuity lips. Fig. 6 shows the same kind of results for a sample coming from the U.T. (AV1112). In this case, the slice is taken in the upper part of the sample. The reaction to water was very limited with respect to the previous case and much slower. However, a modest closure can still be observed. On the other hand, the samples belonging to core EST57261 just $3 \mathrm{~m}$ less deep on site (BH4142 and BV3132) did not show any kind of reaction visible by eye at this resolution. This is likely to be due either to the absence/low proportion of clay component in the material or to the impossibility of water to reach it as a consequence of reduced connected pores. To try to answer to this question, $\mathrm{x}$-ray diffraction mineralogical analyses were performed. They are discussed in the next section.

To better analyse the physical phenomena driving the self-sealing behaviour of the material three experiments on U.A. samples were repeated at a higher resolution $(0.7$ $\mu \mathrm{m})$ at the synchrotron. As an example, Fig. 7 shows the results of a local tomography on sample $\mathrm{H} 2122$. The fracture closing observed at the larger scale (Fig. 5) scale is accompanied by the creation at the small scale of a net of factures (peeling effect).
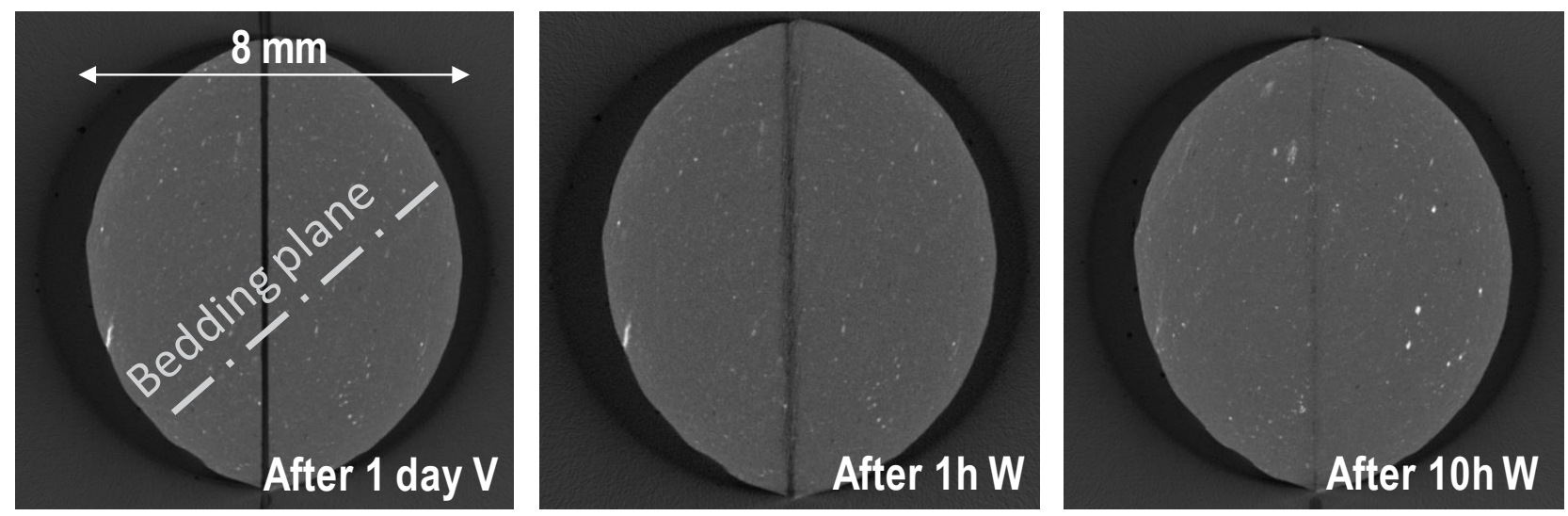

Fig. 5. X-ray images at different steps during test 4142 (U.A.), resolution $13.5 \mu \mathrm{m}$. 

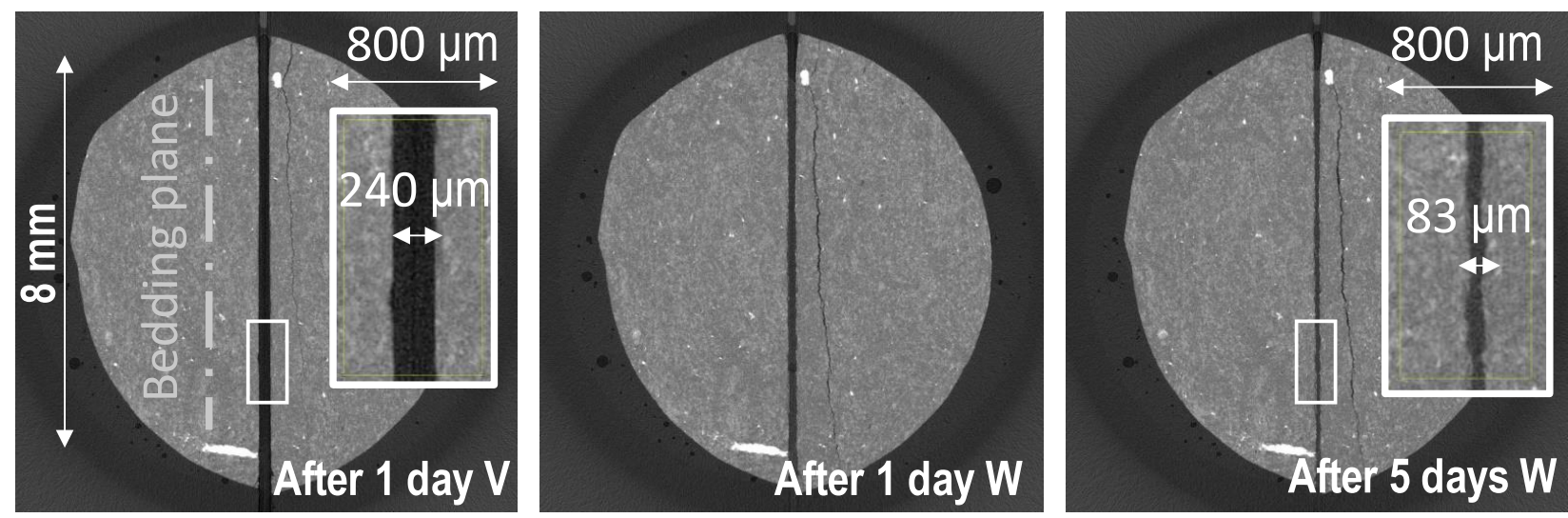

Fig. 6. X-ray images at different steps during test AV1112 (U.T.), resolution $7 \mu \mathrm{m}$.
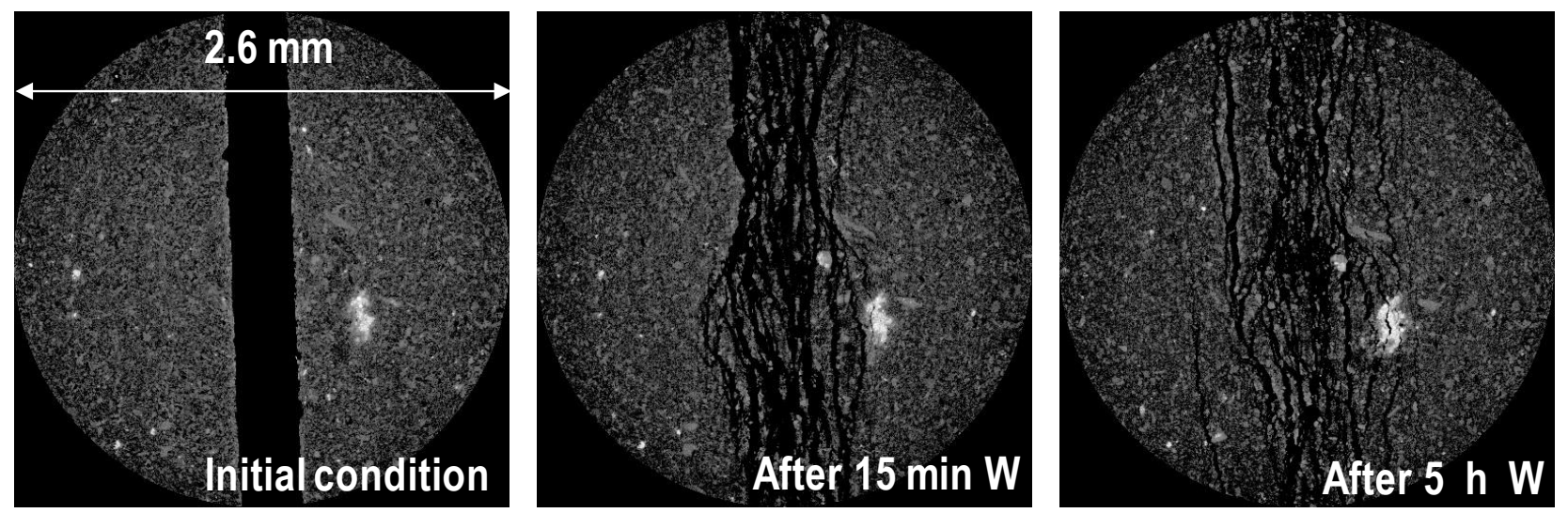

Fig. 7. X-ray images at different steps during test H2122 (U.A.), resolution $0.7 \mu \mathrm{m}$ (bedding plane parallel to the slice).

\subsection{Mineralogical analyses}

According to Conil et al. 2018, the average mineralogical distribution in the COx throughout the whole formation is composed by a clay fraction (phyllosilicates) of $42 \% \pm 11 \%$, a carbonates content of $30 \% \pm 12 \%$, a tectosilicates content of $25 \% \pm 8 \%$, and the other ancillary minerals constitute less than $4 \%$.With the purpose to interpret and justify the different behaviour of the U.T. specimens with respect to the U.A. ones observed experimentally, x-ray diffraction mineralogical analyses were performed on two samples collected respectively from core EST57243 and EST57261. These analyses were carried out at the Isterre Laboratory (Grenoble, France). The results were obtained through the Rietveld method, after identification of the different phases present in the samples. The amorphic phases were not determined. The results are presented in Table 2 . The incertitude in the percentages of the different phases is in the order of \pm 1 $2 \%$. The material from core EST57261 shows an extremely high level of carbonates $(78.1 \%)$ and a low clay (around 9.5\% with smectite around 5.9\%) and tectosilicate $(11.8 \%)$ content. The strong presence of carbonates might justify the very low void ratio measured in the laboratory $(e=0.05)$ and the consequent absence of swelling in contact with water. The material from EST57243 shows a carbonates content (38\%) lower than EST57261 but still higher than the average values expected for COx. The clay content is quite high or in the average $(48.2 \%)$, even if the smectite active clay only represents the $11.9 \%$. The tectosilicates content both higher than EST57261 and the average. The higher clay content associated with the lower carbonates content seems to be coherent with the intermediate response observed for these samples.

Table 2. Results of mineralogical x-ray diffraction analyses on U.T. samples.

\begin{tabular}{|c|c|c|c|c|c|}
\hline \multicolumn{2}{|c|}{ Phase } & \multicolumn{2}{|c|}{$\begin{array}{c}\text { EST57243 } \\
(\%)\end{array}$} & \multicolumn{2}{|c|}{$\begin{array}{c}\text { EST57261 } \\
(\%)\end{array}$} \\
\hline \multirow{3}{*}{ Tectosilicates } & Quartz & 25.5 & \multirow{3}{*}{34.7} & 8.5 & \multirow{3}{*}{11.8} \\
\hline & Plagioclase & 1.7 & & - & \\
\hline & FeldspathK & 7.8 & & 3.3 & \\
\hline \multirow{3}{*}{ Carbonates } & Calcite & 33.2 & \multirow{3}{*}{38.0} & 76.5 & \multirow{3}{*}{78.1} \\
\hline & Ankerite & 2.4 & & 1.6 & \\
\hline & Dolomite & 2.4 & & - & \\
\hline \multirow{3}{*}{ Clay } & Smectite & 11.9 & \multirow{3}{*}{48.2} & 5.9 & \multirow{3}{*}{9.5} \\
\hline & Mica & 24.7 & & 3 & \\
\hline & Chlorite & 11.6 & & 0.3 & \\
\hline \multirow{2}{*}{ Others } & Pyrite & 0.8 & \multirow{2}{*}{1.1} & 0.4 & \multirow{2}{*}{0.4} \\
\hline & Anatase & 0.3 & & - & \\
\hline
\end{tabular}




\section{Conclusions}

The self-sealing response of $\mathrm{COx}$ claystone was experimentally investigated through x-ray tomography. Different fracture sizes, orientations with respect to the bedding plane and position on site were considered. The capacity to close open fractures shown by samples collected in different geological layers was quite different. The reaction to water vapour was limited or absent in all cases at the time frame of the tests (few days). The response to water contact of the material coming from the U.A. was significant and fast: at low resolution (7 to 15 $\mu \mathrm{m})$ the discontinuity seemed to be closed after less than $10 \mathrm{~h}$. Higher resolution $(0.7 \mu \mathrm{m})$ images highlighted a peeling effect at the discontinuity lips, showing that the closure of the main fracture is associated with the creation of micro cracks. However, in such conditions, the hydraulic permeability is still expected to be reduced with respect to the open fracture configuration (Davy et al, 2007; Giot et al., 2018). Samples coming from the U.T. showed absence of very limited reaction even to water contact. Mineralogical x-ray diffraction analyses on these samples revealed a carbonates content much higher than expected which might justify the unexpected response.

The authors would like to thank Andra for the financial support and in particular Nathalie Conil and Jean Talandier for the useful discussions. The collaboration with the colleagues of the Isterre laboratory, Nathaniel Findling and Bruno Lanson, for the mineralogical analyses was also much appreciated. The authors would also like to thank Edward Andò (Laboratoire 3SR), Jelke Dijkstra (Chalmers University of Technology) and Elodie Boller (ESRF) for their assistance at the ESRF.

\section{References}

1. N. Conil, J. Talandier, H. Djizanne, R. de La Vaissière, C. Righini-Waz, C. Auvray, C. Morlot, G. Armand, How rock samples can be representative of in situ condition: A case study of Callovo-Oxfordian claystones, Journal of Rock Mechanics and Geotechnical Engineering, 10, 4, 613-623 (2018).

2. C.A. Davy, F. Skoczylas, J.-D. Barnichon, P. Lebon. Permeability of macro-cracked argillite under confinement: gas and water testing. Physics and Chemistry of the Earth, Parts A/B/C 32 (8):667-680, (2007).

3. R. Giot, C. Auvray and J. Talandier. Self-sealing of claystone under X-ray nanotomography. Geological Society, London, Special Publications, 482, https://doi.org/10.1144/SP482.4, (2018).

4. M. Mohajerani, P. Delage, M. Monfared, A. M. Tang, J. Sulem, B. Gatmiri. Oedometric compression and swelling behaviour of the Callovo-Oxfordian argillite International Journal of Rock Mechanics \& Mining Sciences 48, 606-615 (2011).

5. Q.T. Pham, F. Vales, L. Malinsky, D. Nguyen Minh, H. Gharbi. Effects of desaturation-resaturation on mudstone. Physics and Chemistry of the Earth 32, 646-655, (2007).
6. E. Stavropoulou, E. Andò, A. Tengattini, M. Briffaut, F. Dufour, D. Atkins, \& G. Armand. Liquid water uptake in unconfined Callovo Oxfordian clay-rock studied with neutron and X-ray imaging. Acta Geotechnica, 1-15 (2018).

7. M. Wan, P. Delage, A. M. Tang, J. Talandier. Water retention properties of the Callovo-Oxfordian claystone International Journal of Rock Mechanics \& Mining Sciences 64, 96-104 (2013). 